\title{
Progressive supranuclear palsy
}

\author{
H U Rehman
}

\begin{abstract}
Progressive supranuclear palsy (PSP) or Steele-Richardson-Olszewski syndrome is a neurodegenerative disease of middle and late age. It is under-diagnosed not only by general physicians but also by neurologists. The cause of PSP is not known. Exposure to toxins and viruses has been proposed in the aetiology of PSP without any concrete evidence. The features of PSP resemble those of Parkinson's disease and the two diseases are often confused. Corticobasal degeneration and multisystem atrophy are other differential diagnoses. Despite certain common features with Parkinson's disease, corticobasal degeneration, and mutisystem atrophy, there are important differences that help to differentiate it from these disorders. (Postgrad Med F 2000;76:333-336)
\end{abstract}

Keywords: progressive supranuclear palsy; SteeleRichardson-Olszewski syndrome

Progressive supranuclear palsy (PSP) or Steele-Richardson-Olszewski syndrome is a neurodegenerative disease of middle and late age. Steele et al published the first clinicopathological description of the disorder in $1964,{ }^{1}$ although there are several previous case reports in the literature. ${ }^{23}$

The annual incidence of the disease is 5.3 new cases per 100000 person years and the prevalence of the disease is estimated at 1.39 per 100000 population in the US. ${ }^{4}$ It is likely that these figures are a considerable under-estimate, as many patients with PSP are not diagnosed and die with other diagnoses. ${ }^{5}$ In the UK Parkinson's Disease Society Brain Bank, $6 \%$ of 100 prospectively followed up patients dying with a clinical diagnosis of Parkinson's disease were found to have PSP at necropsy. ${ }^{6}$ The results of the first large scale population prevalence study of PSP have recently been presented. A population of 121608 people was screened for all patients with a mention of "Parkinson's disease", "parkinsonism", "tremor" (with onset after age 50), "Shy-Drager syndrome", "parkinsonism with orthostatic hypotension", and "other extrapyramidal disorders, not otherwise specified", or those who had ever received antiparkinsonian medication. The prevalence rate for PSP was 4.9 per 100000 in this study and the diagnosis of PSP was not previously made in any of these patients. ${ }^{7}$

The incidence of PSP increases with age (1.7 at 50-59 years, 14.7 at $80-99$ years). ${ }^{8}$ Males are affected more commonly than females. ${ }^{9}$

PSP is a sporadic disease, although recently a few familial cases have been reported..$^{10}$ All the familial cases except one had a recessive mode of inheritance. Moreover Higgins et al reported over-representation of tau $\tau$ alpha 1 allele and the $\tau \alpha 1 \alpha 1$ genotype in individuals with PSP and the $\tau$ polymorphism to be in linkage disequilibrium with the PSP disease locus when a recessive inheritance model was employed. ${ }^{12}$

The cause of PSP is not known. Exposure to toxins and viruses has been proposed in the aetiology of PSP without any concrete evidence. ${ }^{13}{ }^{14}$ Abnormalities of the gene leading to the formation of abnormal proteins that in turn favour the development of neurofibrillary tangles are currently under investigation. ${ }^{15}$

\section{Clinical features}

The onset of symptoms in PSP is insidious. Age of onset is usually between 55 and 70 years. ${ }^{16}$ Postural instability, supranuclear vertical gaze palsy, rigidity with abnormal posturing of the neck (retrocollis), frontal lobe symptoms, and dementia are the main features of PSP. Pyramidal and cerebellar signs are variable. Postural instability and falls are the most common presenting features and patients have a slow, unsteady gait. Bradykinesia is classically symmetric and rigidity is axial, and both are usually unresponsive to levodopa therapy. Dysarthria and dysphagia due to pseudobulbar palsy are early symptoms. Frontal lobe symptoms also develop early in the course of the disease. Diplopia, blurred vision, burning eyes, and light sensitivity are other visual symptoms, occurring early in the course of the disease. ${ }^{5}$

Slowing of saccades and hypometric saccades may precede the supranuclear limitation of vertical gaze. ${ }^{17}{ }^{18}$ Supranuclear vertical gaze palsy may be followed by horizontal gaze abnormalities. Supranuclear vertical gaze palsy may occasionally be absent, ${ }^{19}{ }^{20}$ but when present affects first vertical gaze and then horizontal gaze unlike most other disorders causing a supranuclear gaze palsy (see box 1). These include dementia with Lewy bodies, corticobasal degeneration, vascular parkinsonism, Creutzfeldt-Jakob disease, and Whipple's disease. ${ }^{21-23}$ Because limitation of upward gaze is more common than limitation of downward gaze in neurodegenerative disorders, and because there is also a certain degree of upward gaze restriction with aging, limitation of downward gaze is considered more specific for the diagnosis of PSP. ${ }^{24}$ Dysfunction of voluntary

Box 1: Causes of supranuclear gaze palsy

- Steele-Richardson-Olszewski syndrome

- Lewy body dementia

- Corticobasal degeneration

- Vascular parkinsonism

- Creutzfeldt-Jakob disease

- Whipple's disease
Submitted 20 April 1999 Accepted 22 September 1999 
eyelid movements is a characteristic feature of PSP and includes reduced blinking, voluntary eyelid motility impairment, and even full blown blepharospasm. Slowing of eye opening or eye closure are late signs. The patients may fail to suppress their vestibuloocular reflex and may have abnormalities of convergence. ${ }^{25} \mathrm{~A}$ visual glabellar reflex (inability to suppress a blink to a bright light) may become positive. ${ }^{18}$

Motor difficulty particularly involves axial more than limb muscles. In the axial musculature, neck muscles are more affected than trunk muscles. ${ }^{26}$ Dysarthria is an early feature and is of mixed type with a combination of spastic, hypokinetic, and ataxic components. ${ }^{27}$ Pyramidal signs develop in one third of patients.

Disturbances of thought, perseveration, difficulty with planning and problem solving, and behavioural disturbances including apathy, disinhibition, depression, and anxiety are the usual frontal lobe symptoms. ${ }^{28-30}$ As a result of the frontal lobe disturbance the PSP patient may jump to his or her feet from a sitting position without thinking only to topple backwards into the chair because of postural instability. This is known as the "rocket sign".

The symptoms and signs progress steadily and most patients eventually are wheelchair bound and may require a feeding tube.

Median survival time from symptom onset is 5.6 years (range $2-16.6$ years). ${ }^{8}$ Falls during the first year, early dysphagia, and incontinence are poor prognostic signs. ${ }^{5}$ Pneumonia is the most common cause of death.

\section{Differential diagnosis (see box 2)}

PSP should be differentiated from Parkinson's disease. This can prove difficult at an early stage if the ophthalmoplegia and postural instability only develop late in the disease as can happen with some PSP patients. Parkinsonian signs are usually asymmetric in patients with Parkinson's disease. Early falls and a limited response to L-dopa treatment will point to a diagnosis of PSP. Dysphagia generally occurs early in the course of PSP in contrast to Parkinson's disease in which it appears only in middle to advanced stages. PSP progresses much faster than Parkinson's disease.

In addition to its asymmetric onset other features of corticobasal degeneration which differentiate it from PSP include unilateral ideomotor apraxia, unilateral cortical sensory signs, unilateral visual neglect, unilateral dystonia, and segmental myoclonus. PSP patients may also exhibit ideomotor apraxia, but this is usually mild and bilateral. ${ }^{31}$

Box 2: Differential diagnosis of progressive supranuclear palsy

- Parkinson's disease

- Corticobasal degeneration

- Multiple system atrophy

- Pick's disease

- Alzheimer's disease

- Postencephalitic parkinsonism
In multiple system atrophy autonomic signs are prominent and cerebellar disturbances are common while cognition is preserved.

PSP is occasionally confused with Pick's disease or Alzheimer's disease. However cortical dementia is uncommon in PSP. ${ }^{32}$

\section{Neuropathology}

The principal macroscopic abnormality is severe pigment depletion in the substantia nigra, which is orange discoloured and shrunken. Pigment is also reduced in the locus coeruleus. ${ }^{19}$

On light microscopy the substantia nigra, subthalamus, and pallidum are degenerate. Neurofibrillary tangles occur in a widespread distribution including hippocampus, parahippocampus, caudate, putamen, pallidum, subthalamus, substantia nigra, frontal cortex, insular region, colliculi, periaqueductal grey, red nucleus, nucleus basis pontis, inferior olive and dentate. ${ }^{19}$ The National Institute of Neurological Disorders and Stroke (NINDS) criteria for PSP require a high density of neurofibrillary tangles and neuropil threads in at least three of the following sites: pallidum, subthalamic nucleus, substantia nigra or pons, and a low to high density in at least three of the following sites: striatum, oculomotor complex, medulla, or dentate nucleus. Neuronal loss and gliosis are variable. ${ }^{33}$ Amyloid deposits and neuritic plaques are notably absent.

The major neurotransmitter systems affected in PSP are the dopaminergic nigrostriatal pathway, the GABAergic and cholinoceptive striatal neurones and the cholinergic brainstem and basal forebrain nuclei. ${ }^{34-36}$ Marked degeneration of several cholinergic nuclei has been found. Nearly $80 \%$ of the cholinergic neurones are lost in the interstitial nucleus of Cajal. Loss of cholinergic cells in the nucleus pontis centralis caudalis may be related to the disturbances of horizontal saccades. Choline acetyltransferase activity is also reduced in many brain regions, including striatum, cerebral cortex, and substantia innominata. ${ }^{37}$

Although there is degeneration of the nigrostriatal dopaminergic system, the mesolimbic and mesocortical dopaminergic projection systems seem to be relatively spared..$^{38} \mathrm{D}_{2}$ dopamine receptor binding sites are decreased in the caudate nucleus and putamen in PSP patients. ${ }^{39}$ Dopamine and homovanillic acid contents are markedly reduced in the caudate nucleus and putamen, but normal in the nucleus accumbens and cerebral cortex. ${ }^{37} 40$

The density of the GABAergic neurones has also been found to be significantly lower in the caudate nucleus, the ventral striatum, the internal pallidum, and the external pallidum in patients with PSP. ${ }^{41}$

Serotonin-S2 receptors are decreased in the temporal cortex of patients with Parkinson's disease and PSP. ${ }^{42}$ Caudate and putamen opioid receptor binding is also significantly reduced in PSP patients compared to normal controls and Parkinson's disease patients. ${ }^{43}$ Other neurotransmitter abnormalities found in patients with PSP are raised glutamate content in the nucleus accumbens, raised taurine 
concentrations in the nucleus accumbens, globus pallidus, and substantia nigra, and increased contents of glycerophosphoethanolamine in most brain regions. ${ }^{44}$

\section{Clinical diagnostic criteria}

Several criteria for the diagnosis of PSP have been proposed. To improve diagnostic accuracy and standardisation, the NINDS and the Society for Progressive Supranuclear Palsy have proposed the following criteria. ${ }^{18}$

For possible PSP, onset at age 40 or later, gradual progression, and either vertical supranuclear palsy, or slowing of vertical saccades and prominent postural instability with falls in the first year after disease onset, are mandatory inclusion criteria (see box 3). When both supranuclear vertical palsy and prominent postural instability with falls in the first year of disease onset are present, the diagnosis becomes probable. Mandatory exclusion criteria include recent history of encephalitis, alien limb syndrome, cortical sensory deficits, focal frontal or temporoparietal atrophy, hallucinations or delusions unrelated to dopaminergic therapy, cortical dementia of Alzheimer's type, prominent early cerebellar symptoms, unexplained dysautonomia, severe asymmetric parkinsonian signs (that is, bradykinesia), neuroradiological evidence of relevant structural abnormality and Whipple's disease confirmed by polymerase chain reaction, if indicated (see box 4). Supportive features are symmetric akinesia or rigidity, proximal more than distal, retrocollis, poor or absent response to levodopa therapy, early dysarthria or dysphagia and early cognitive impairment including at least two of the following: apathy, impaired abstract thought, decreased verbal fluency, imitation behaviour, and frontal release signs. Definite PSP is a clinicopathological diagnosis.

\section{Investigations}

PSP is a clinical diagnosis but some investigations may be helpful in supporting the diagnosis or excluding related disorders. Electrooculographic recording can be useful in differentiating PSP from related conditions. ${ }^{17}$ Patients with PSP have hypometric horizontal voluntary saccades of normal latency, while patients with corticobasal degeneration show opposite results. Patients with Parkinson's disease or striatonigral degeneration have saccades of normal latency and amplitude.

Box 3: Mandatory inclusion criteria for the diagnosis of progressive supranuclear palsy

- Onset at age 40 or later.

- Gradually progressive disorder.

- Vertical supranuclear gaze abnormalities.

- Prominent postural instability with tendency to falls in the first year after symptom onset Presence of both vertical supranuclear ophthalmoparesis and prominent postural instability with falls within 1 year of symptom onset makes the diagnosis of PSP probable.
Box 4: Mandatory exclusion criteria for the diagnosis of progressive supranuclear palsy

- History compatible with encephalitis lethargica.

- Alien hand syndrome, cortical sensory. deficits, focal frontal, or temporoparietal atrophy.

- Hallucinations or delusions unrelated to dopaminergic therapy.

- Cortical dementia of Alzheimer type.

- Prominent cerebellar symptomatology or unexplained dysautonomia.

- Severe asymmetry of parkinsonian signs.

- Neuroradiological evidence of relevant structural abnormality.

- Whipple's disease confirmed by polymerase chain reaction, if indicated.

Absent orbicularis oculi responses to median nerve electrical stimuli and severely reduced orbicularis oculi responses to acoustic startling stimuli have been shown, reflecting the impairment of reflex brainstem function. ${ }^{45}{ }^{46}$ Absent orbicularis oculi response on median nerve stimulation is specific for PSP and does not occur in other parkinsonian syndromes.

Magnetic resonance imaging (MRI) may show thinning of the quadrigeminal plate and atrophy of the midbrain and the region around the third ventricle, supporting a diagnosis of PSP $^{47}$ Atrophy of the corpus callosum with anterior predominance has been shown to be associated with cognitive impairment in PSP. ${ }^{48}$ The main value of computed tomography and MRI is to exclude other diagnoses such as corticobasal degeneration (asymmetric atrophy in the parietal area), multiple system atrophy (atrophy of the pons, middle cerebellar peduncles and cerebellum), multi-infarct dementia, hydrocephalus, and tumours.

Evoked potentials, polysomnography, and positron emission tomography are research tools and may prove helpful in the future to support an early diagnosis of PSP.

\section{Treatment}

At present there is no effective treatment of PSP. Dopaminergic replacement therapy is only transiently or mildly effective in relieving some of the symptoms. It is however, worth trying because sometimes useful benefit is obtained. In spite of the severe loss of cholinergic neurones in the brains of patients with PSP, marginal or no benefits are seen after administration of physostigmine, a cholinesterase inhibitor, or of a cholinergic agonist. ${ }^{49}$ Isolated reports of improvement in symptoms after treatment with trazodone, ${ }^{50}$ idazoxan, ${ }^{51}$ methysergide, ${ }^{52}$ L-threo-DOPS, ${ }^{53}$ and amitriptyline $\mathrm{e}^{54}$ are found in the literature. However no persistent beneficial effect has been seen. More research is needed before any of these can be recommended for the treatment of PSP.

Blepharospasm and levator inhibition may be treated with botulinum toxin injections, but the success rate in the latter is only about $50 \%$. Artificial tears may help to avoid exposure 
keratitis. Antidepressants may help emotional apathy, depression and pseudobulbar crying. Supportive treatment includes provision of weighted, soft wheeled walkers or a wheelchair, communication aids, referral to physical and occupational therapists, and regular assessment of swallowing by a speech therapist.

1 Steele JC, Richardson JC, Olszewski J. Progressive supranuclear palsy. Arch Neurol 1964;10:333-59.

2 Chavany JA, van Bogaert I, Godlewski S. Sur un syndrome de rigidité à predominance axiale, avec perturbation des automatismes oculo-palbébraux d'origine encéphalitique. $958-62$

3 Janischewsky A. Un cas de maladie de Parkinson avec syndrome pseudobulbaire et pseudo-ophthalmoplégique: quelques considérations sur la pathogenie de cette maladie. Rev Neurol (Paris) 1909;17:831-2.

4 Golbe Li, Davis PH, Schoenberg BS, et al. Prevalence and hatural history of progressive supranuclear palsy. Neurology 1988;38:1031-4

5 Litvan I, Mangone CA, McKee A, et al. Natural history of progressive supranuclear palsy (Steele-RichardsonOlszewski syndrome) and clinical predictors of survival: a linicopathological study. $\mathcal{F}$ Neurol Neurosurg Psychiatry 1996;60:615-20.

6 Hughes AJ, Daniel SE, Kilford L, et al. Accuracy of clinical diagnosis of idiopathic Parkinson's disease: a clinicopathological study of 100 cases. $\mathcal{F}$ Neurol Neurosurg Psychiapathological study of 1 .

7 Schrag AE, Ben-Shlomo Y, Quinn NP. The population prevalence of atypical parkinsonian disorders. Neurology prevalence of atypical

8 Bower JH, Maraganore DM, McDonnell SK, et al. Incidence of progressive supranuclear palsy and multiple system atrophy in Olmsted County Minnesota, 1976 to 1990. Neurology 1997;49:1284-8.

9 Santacruz P, Uttl B, Litvan I, et al. Progressive supranuclear palsy: a survey of disease course. Neurology 1998;50:163747.

10 Ohara S, Kondo K, Morita H, et al. Progressive supranuclear palsy-like syndrome in two siblings of a consanguineous marriage. Neurology 1992;42:1009-14.

11 Brown J, Lantos P, Stratton M, et al. Familial progressive supranuclear palsy. $\mathcal{F}$ Neurol Neurosurg Psychiatry 1993;56: 473-6.

12 Higgins JJ, Litvan I, Pho LT, et al. Progressive supranuclear palsy is a recessive disorder in linkage disequilibrium with the tau and not the alpha-synuclein gene. Neurology the tau and

13 Davis PH, Golbe LI, Duvoisin RC, et al. Risk factors for progressive supranuclear palsy. Neurology 1988;38:1546-52.

14 Golbe LI, Rubin RS, Cody RP, et al. Follow-up study of risk factors in progressive supranuclear palsy. Neurology 1996; 47:148-54.

15 Conrad C, Andreadis A, Trojanowski JQ, et al. Genetic evidence for the involvement of tau in progressive supranuclear palsy. Ann Neurol 1997;41:277-81

6 Brusa A, Mancardi GL, Bugiani O. Progressive supranuclear palsy 1979: an overview. Ital f Neurol Sci 1980;4:20522.

17 Vidailhet M, Rivaud S, Gouider-Khouja N, et al. Eye movements in parkinsonian syndromes. Ann Neurol 1994;35: 420-6.

18 Litvan I, Agid Y, Calne D, et al. Clinical research criteria for the diagnosis of progressive supranuclear palsy (Steele-
Richardson-Olszewski syndrome). Report of the NINDSSPSP international workshop. Neurology 1996;47:1-9.

19 Daniel SE, De Bruin VMS, Lees AJ. The clinical and pathological spectrum of Steele-Richardson-Olszewski syndrome (progressive supranuclear palsy): a reappraisal. Brain 1995; 118:759.

20 Dubas F, Gray F, Escourolle R. Steele-RichardsonOlszewski disease without ophthalmoplegia. Six clinicoanatomic cases. Rev Neurol (Paris) 1983;139:407-16.

21 De Bruin VM, Lees AJ, Daniel SE. Diffuse Lewy body disease presenting with supranuclear gaze palsy, parkinsonism,
and dementia: a case report. Mov Disord 1992;7:355-8.

22 Amarenco P, Roullet E, Hannoun L, et al. Progressive supranuclear palsy as the sole manifestation of systemic Whipple's disease treated with pefloxacine (letter). $\mathcal{F}$ Neurol Neurosurg Psychiatry 1991;54:1121-2.

23 De Bruin VM, Lees AJ. Subcortical neurofibrillary degeneration presenting as Steele-Richardson-Olszewski and other related syndromes: a review of 90 pathologically verified cases. Mov Disord 1994;9:381-9.

24 Colosimo C, Albanese A, Hughes AJ, et al. Some specific clinical features differentiate multiple system atrophy (stria-
tonigral variety) from Parkinson's disease. Arch Neurol tonigral variety)

25 Troost B, Daroff R. The ocular motor defects in progressive supranuclear palsy. Ann Neurol 1977;2:397-403.

26 Tanigawa A, Komiyama A, Hasegawa O. Truncal muscle tonus in progressive supranuclear palsy. $\mathcal{F}$ Neurol Neurosurg Psychiatry 1998;64:190-6.

27 Kluin KJ, Foster NL, Berent S, et al. Perceptual analysis of speech disorders in progressive supranuclear palsy. Neurology 1993;43:563-6.
28 Grafman J, Litvan I, Gomez C, et al. Frontal lobe function in progressive supranuclear palsy. Arch Neurol 1990;47:553-8.

29 Pillon B, Blin J, Vidailhet M, et al. The neuropsychological pattern of corticobasal degeneration: comparison with progressive supranuclear palsy and Alzheimer's disease. Neurology 1995;45:1477-83.

30 Litvan I, Mega MS, Cummings JL, et al. Neuropsychiatric aspects of progressive supranuclear palsy. Neurology 1997; 47:1184-9.

31 Leiguarda RC, Pramstaller PP, Merello M, et al. Apraxia in Parkinson's disease, progressive supranuclear palsy, multiple system atrophy and neuroleptic-induced parkinsonism. Brain 1997;120:75-90.

32 Pillon B, Dubois B, Ploska A, et al. Severity and specificity of cognitive impairment in Alzheimer's, Huntington's, and Parkinson's diseases and progressive supranuclear palsy. Neurology 1991;41:634-43.

33 Hauw JJ, Daniel SE, Dickson D, et al. Preliminary NINDS neuropathologic criteria for Steele-Richardson-Olszewski syndrome (progressive supranuclear palsy). Neurology 1994; 44:2015-19.

34 Agid Y, Javoy-Agid F, Ruberg M, et al. Progressive supranuclear palsy: anatomoclinical and biochemical considerations. Adv Neurol 1987;45:191-206.

35 Malessa S, Hirsch EC, Cervera P, et al. Catecholaminergic systems in the medulla oblongata in parkinsonian syndromes: a quantitative immunohistochemical study in Parkinson's disease, progressive supranuclear palsy, and striatonigral degeneration. Neurology 1990;40:1739-43.

36 Malessa S, Hirsch EC, Cervera P, et al. Progressive supranuclear palsy: loss of choline-acetyltransferase-like immunoreactive neurons in the pontine reticular formation. Neurology 1991;41:1593-7.

37 Ruberg M, Javoy-Agid F, Hirsch E, et al. Dopaminergic and cholinergic lesions in progressive supranuclear palsy. Ann Neurology 1985;18:523-9.

38 FitzGibbon EJ, Carl JR, Litvan I. Horizontal, vertical, and oblique saccades in progressive supranuclear palsy. Invest Ophthalmol Vis Sci 1988;29:344.

39 Eric van Royen, Verhoeff NFLG, Speelman JD, et al. Multiple system atrophy and progressive supranuclear palsy. Diminished striatal $\mathrm{D}_{2}$ dopamine receptor activity demonstrated by ${ }^{123} \mathrm{I}-\mathrm{IBZM}$ single photon emission computed tomography. Arch Neurol 1993;50:513-6.

40 Kish SJ, Chang LJ, Mirchandani L, et al. Progressive supranuclear palsy: relationship between extrapyramidal disturbances, dementia, and brain neurotransmitter markers. Ann Neurol 1985;18:530-6.

41 Levy $\mathrm{R}$, Ruberg $\mathrm{M}$, Herrero MT, et al. Alterations of GABAergic neurons in the basal ganglia of patients with progressive supranuclear palsy: an in situ hybridization study of $\mathrm{GAD}_{67}$ messenger RNA. Neurology 1995;45:12734 .

42 Maloteaux JM, Laterre EC, Laduron PM, et al. Decrease of serotonin-S2 receptors in temporal cortex of patients with Parkinson's disease and progressive supranuclear palsy. Mov Disord 1988;3:255-62.

43 Burn DJ, Rinne JO, Quinn NP, et al. Striatal opioid receptor binding in Parkinson's disease, striatonigral degeneration and Steele-Richardson-Olszewski syndrome. A $\left({ }^{11} \mathrm{C}\right)$ diprenorphine PET study. Brain 1995;118:951-8.

44 Perry TL, Hansen S, Jones K. Brain amino acids and glutathione in progressive supranuclear palsy. Neurology 1988;38:943-6.

45 Vidailhet M, Rothwell JC, Thompson PD, et al. The auditory startle response in the Steele-RichardsonOlszewski syndrome and Parkinson's disease. Brain 1992; 115:1181-92.

46 Valls-Sole J, Valldeoriola F, Tolosa E, et al. Distinctive abnormalities of facial reflexes in patients with progressive supranuclear palsy. Brain 1997;120:1877-83.

47 Litvan I. Progressive supranuclear palsy: staring into the past, moving into the future. The Neurologist 1998;4:13-20.

48 Yamauchi H, Fukuyama H, Nagahama Y, et al. Atrophy of the corpus callosum, cognitive impairment, and cortical hypometabolism in progressive supranuclear palsy. Ann Neurol 1997;41:606-14.

49 Litvan I. Cholinergic approaches to the treatment of progressive supranuclear palsy. F Neural Transm Suppl 1994; 42:275-81

50 Kato E, Takahashi S, Abe T, et al. A case of progressive supranuclear palsy showing improvement of rigidity, nuchal dystonia and autonomic failure with trazodone. Rinsho Shinkeigaku-Clin Neurol 1994;34:1013-7.

51 Cole DG, Growdon JH. Therapy for progressive supranuclear palsy: past and future. $\mathcal{F}$ Neural Transm Suppl 1994;42: 283-90.

52 Di Trapani G, Stampatore P, La Cara A, et al. Treatment of progressive supranuclear palsy with methysergide. A clinical study. Ital ₹ Neurol Sci 1991;12:157-61.

53 Maruyama T, Tamaru F, Yamagisawa N. A case of progressive supranuclear palsy dramatically improved with L-threo3,4-dihydroxyphenylserine. Rinsho Shinkeigaku-Clin Neurol 1992;32:606-11.

54 Asanuma M, Hirata $\mathrm{H}$, Kondo $\mathrm{Y}$, et al. A case of progressive supranuclear palsy showing marked improvements of frontal hypoperfusion, as well as parkinsonism with amitriptyline. Rinsho Shinkeigaku-Clin Neurol 1993;33:317-21. 